\title{
Monitoring and Evaluation for Quality Service Delivery in Pre-Primary Schools in Murang'a County, Kenya
}

\author{
Kamau Joyce Muthoni', Ong'ang'a H. Ouko ${ }^{2}$, Kimamo Githui ${ }^{3}$ \\ ${ }^{1}$ Mount Kenya University, Thika, Kenya \\ ${ }^{2}$ School of Education, Kenyatta University, Nairobi, Kenya \\ ${ }^{3}$ School of Education, Mount Kenya University, Thika, Kenya \\ Email: jmkamau@mku.ac.ke
}

How to cite this paper: Muthoni, K. J., Ouko, O. H., \& Githui, K. (2021). Monitoring and Evaluation for Quality Service Delivery in Pre-Primary Schools in Murang'a County, Kenya. Open Journal of Social Sciences, 9, 409-427.

https://doi.org/10.4236/jss.2021.95022

Received: April 10, 2021

Accepted: May 22, 2021

Published: May 25, 2021

Copyright ( 2021 by author(s) and Scientific Research Publishing Inc. This work is licensed under the Creative Commons Attribution International License (CC BY 4.0).

http://creativecommons.org/licenses/by/4.0/

\begin{abstract}
Monitoring and evaluation of the National Early Childhood Development (ECD) Policy framework in Kenya which has been in place since the year 2006 accompanied by a service guideline is important in promoting its implementation. The extent to which the policy is implemented would have a direct pairing with the quality of early childhood service delivery. The purpose of this study was to investigate the levels of monitoring and evaluation in implementation of the National Early Childhood Development Policy framework for quality service delivery in pre-primary schools in Kenya. Conflict Ambiguity Model of Policy implementation, Broffenbrenner's Ecological systems theory and Lilian Katz perspective on quality theory were used. Mixed methods research approach and concurrent triangulation design guided the study. Data was collected using questionnaire, observation schedule and interview guides. Instruments reliability coefficient was 0.85 . Qualitative data was analyzed thematically and quantitative data was analyzed using descriptive and inferential statistics. The findings indicated that a strong relation between monitoring and evaluation at $p<0.001$ and quality service delivery in pre-primary schools. The study concluded that goals of the ECD policy in Kenya of enhancing quality service delivery may not be realized thus compromising on the quality of pre-primary education. Subsequently, the study recommended that the county government should allocate adequate resources both financial and human to ensure regular monitoring of pre-primary schools in an effort to promote actualization of policy guidelines in delivery of quality services and consequently promoting positive child development outcomes.
\end{abstract}




\section{Keywords}

Monitoring and Evaluation, Policy Implementation, Early Childhood

Development, Quality Service Delivery, Pre-Primary Schools

\section{Introduction}

Policy in any education plays a critical role in ensuring quality of any educational programme. ECD policy framework was published in 2006 in Kenya to ensure quality of service delivery in the area of early childhood education. This was catalyzed by two global policies which are Education for All (EFA) and Millenium Development Goals (MDG) as outlined in these documents (UNESCO, 2000; UN, 2000). These policies obligated nations to expand and enhance comprehensive ECD programmes. As a result, the government of Kenya through Sessional paper No. 1 of 2005 suggested advancement of an all-inclusive ECD policy framework and service standard guidelines. The developed policy was in cognizant of the declining status of child development in Kenya, significance of early developmental years and benefits of investing in early years (Republic of Kenya, 2006a).

Despite the fact that the document was developed and approved for implementation there are various challenges encountered in delivery of ECD services (Murunga, 2016). This indicates that there exist variations between what is in the policy document and the practice hence the need for the current study to investigate implementation of ECD policy influence on quality service delivery. Early years are very critical to child development as it is a stage in life when children acquire concepts, skills, and attitudes which lay a foundation for lifelong learning. Therefore, any gap noted in service delivery should be attended to with immediacy and appropriately. This is because services for young children play a crucial role in the development of inherent potential and has the potential of reversing the effect of deprivation (Dawes, Bray, Kvalsvig, Kafaar, Rama, \& Richter, 2004).

Implementation of ECD policy framework should translate to quality service delivery and improved children outcomes in terms of holistic development. The goal of ECD policy framework in Kenya is to enhance access, equity, and quality services for all children from conception to eight years (Republic of Kenya, 2006a). To actualize these goals, a service standard guideline was developed alongside the policy framework document to ensure that quality services are delivered efficiently and effectively in Pre-primary schools through effective implementation of the ECD programs. However, despite all the efforts put in place more than a decade down the line, there are pertinent issues regarding quality in Pre-primary schools in Kenya.

These issues relate to provision of appropriate physical environment, nutritional, and health services in Pre-Primary schools in Kenya. The ECD service 
guideline candidly outlines practices which should be observed to address the aforementioned issues to enhance quality service delivery. Nevertheless, hardly are the guidelines observed on the ground to ensure appropriate size of the compound and classroom, furniture for the teacher and children, infrastructure for children with special needs, toilets, water, play and learning environment and appropriate outdoor play space. All these provisions do vary despite the fact that there are standard service guidelines which should be observed by all Pre-primary schools (Republic of Kenya, 2006b).

According to UNICEF (2011), the quality of physical environment is strongly linked to learning which takes place in an ECD center. This implies that without quality physical environment the expected outcomes in terms of holistic development of the child may be below the par and the child potential is not be optimally nurtured. Physical settings play a crucial part in determining youngsters' welfare, cheerfulness, imagination, and level of liberation as well as defining the excellence of children's education and involvements (ACECQA, 2013). Other international research studies, which include (Royal College Position Statement, 2014; Harvard Centre on the Developing Child, 2010; Pence \& Pacini-Ketchabaw, 2008) have proven that quality ECD intermediations such as training and parental care impact positively on child development in cognitive, health and social spheres. This implies that ECD deserves attention from all stakeholders if nations are committed to the international agenda of achieving equity.

Moige (2012) in an assessment of parents' level of satisfaction with the quality of Pre-Primary education investigated quality indicators influencing parents' level of satisfaction. The study established that parents especially from low income had very low-level of satisfaction with the service delivered in Pre-primary schools. The study also recommended the need to have qualified teachers engaged. However, the study did not investigate the influence of the ECD policy implementation on quality service delivery. Therefore, with a policy framework in place whose goal is to enhance quality service delivery, it becomes paramount to conduct a study to investigate the influence of monitoring and evaluation of the implementation process on quality service delivery.

Development of a comprehensive ECD policy framework calls for a comprehensive monitoring and evaluation system to monitor implementation process as well as evaluate effectiveness of the policy. According to (Vitiello \& Kools, 2010) in developing an effective monitoring and evaluation system the following issues should be clearly outlined; what to monitor, who to monitor, and the cost of conducting monitoring and evaluation to enhance sustainability of the activities. Sustainability of any monitoring and evaluation system requires it to be strategically positioned in a well able ministry. This ensures that monitoring information and evaluation findings are judged and valued by key stakeholders and used in pursuit of good governance (Mackay, 2006). However, monitoring and evaluation system varies with the context hence no single system can successfully work in different contexts (Tarsilla, 2014). Monitoring and evaluation is coupled by many challenges especially in Africa context. Nevertheless, there 
exist success stories of effective monitoring and evaluation in some countries, which have developed best practices model which can be emulated by other countries. This is despite the fact that emulation can be very controversial since each nation is unique but there is always something to learn from successful nations in monitoring and evaluation.

In developed nations like Australia, United States, and United Kingdom monitoring and evaluation employ tools and methods which focus on: performance indicators, rapid reviews, impact evaluations, and performance audits (Lahey, 2005). Such a focus is worth noting by any nation that wishes to improve its monitoring and evaluation systems. However, sustainability of such a system may not be possible in developing countries which are greatly affected by scarcity of resources. Therefore, any monitoring and evaluation system should also be contextualized to available resources.

Many countries in Africa have developed comprehensive policy frameworks for ECD. However even with policies in place many countries continue to struggle with provision of quality education, health and social protection services for all children and their families (UNICEF, 2017). Enhancing access to quality and inclusive ECE requires strict adherence to policy guidelines at the national and grassroots levels a practice that requires strong stake collaborations and efficient monitoring of ECE practices. However, it is estimated that 250 million children $(43 \%)$ younger than 5 years of age in low and middle income countries are at the risk of sub-optimal development into adulthood due to exposure to the risk factors of poverty and stunting (Lu, Black, \& Richter, 2016).

Monitoring and evaluations of ECD programmes in most African countries is dominated by international donors. These donors perpetuate donor-centric features by imposing external information Africa assessment systems thus depressing the creation of dependable African information (Carman, 2007; Fowler, 1997; Hwang \& Powell, 2009). As a result, tools for appraisals used in Africa are derived from developed nations and are not modified and adapted to the African context (Tarsilla, 2014). This implies that information and findings from monitoring and evaluations may not necessarily reflect the true picture on the ground in implementation of ECD programmes which also fail at times to reflect an in-depth knowledge of African approaches to ECD as they attempt to measure up to standards of some developed countries. It's therefore against this background that this study sought to explore the effects of monitoring and evaluation on the quality of service delivery for the early childhood children in Murang'a Kenya.

In Kenya according to ECD service guidelines, before any new institution is established an investigative analysis should be conducted by the concerned ministry. All ECDE centres should be monitored at least twice a year by Quality Assurance and Standard Officers (QASOs). QASOs and ECD county officers are expected to work together and prepare a report for submission to the District Education Officers for action. The policy further recognizes the importance of collaboration and outlines that ECD committee, parents, members of the com- 
munity and other participants shall be educated on how to appraise practices in pre-primary schools. The listed parties are expected to conduct action oriented monitoring and evaluation then information gathered is used for improving services for young children (Republic of Kenya, 2006b). However, currently it is not known whether monitoring and evaluation of ECD programmes in Kenya is effective since there are no studies that have focused on the aspect. Therefore, the current study investigated the extent of adherence to policy guidelines.

\section{Statement of the Problem}

Effective monitoring and evaluation of the ECD policy implementation would be evidenced by presence of a standard physical environment with adequate physical facilities, hiring of qualified and competent teachers who utilize appropriate pedagogical practices as well as suitable nutritional and healthy social environment. However, according to Murang'a County initiative (2015) it is documented that Pre-Primary schools have poor infrastructure and there is poor delivery of content in some schools implying that children are receiving poor foundation of the basic learning concepts. Consequently, Murang'a County has been experiencing low enrollment to primary schools, high levels of repetition and drop-out in Early Childhood level of Education (Muchau, 2015). The scenario indicates existence of a gap between policy guidelines and practice. This is despite the fact that Early Childhood services are now devolved to Counties and one would expect that the situation has improved. However, observations and reports from the County Director of Education in Murang'a indicate that the status quo has persisted over the last five years. Therefore, the study sought to fill the gap by assessing if monitoring and evaluation of ECD policy implementation enhances delivery of quality services in Pre-Primary schools in Murang'a County. It is expected that the findings of this study will provide useful information on the extent to which ECD policy has been implemented in Kenya and give recommendations to improve on quality of services for the child.

\section{Theoretical Framework}

The study employed three theories; the first theory presented a model of policy implementation since the study was dealing with ECD policy implementation and like any other policy it experiences ambiguities and conflicts during the implementation process. Therefore, this theory illuminates the four levels of the policy implementation process which include administrative, political, experimental, and symbolic levels relating each to the policy in focus. In each of the levels challenges encountered in the process of implementation as well as the roles of the various participants such as the government, and local actors can be established through monitoring and evaluation. Current study focused on whether monitoring and evaluation is regularly done by ECD county officers to promote quality services in pre-primary schools.

The second theory is by Bronfenbrenner (1979) who records that individuals 
go through different experiences in different levels of the environment as they interact with each other. The experiences do impact on an individual as well as the institutions in terms of development. This theory was relevant to the current study because monitoring and evaluation outcomes show the extent to which roles are adhered to by the relevant stakeholders at the school level to enhance quality service delivery in pre-primary schools.

Lastly, the third theory, was Lilian Katz perspective on quality, the theory addressed the dependent variables, that is, indicators of quality service delivery in Pre-primary schools. This theory illuminates on the perspectives of quality from different points of view which this study put into consideration. Firstly, the indicators of quality service delivery in this study such as the physical environment represent top-down perspective on the quality of physical infrastructure from the lens of an adult. Secondly, the social environment reveals the nature of quality as experienced by children that is the bottom-up perspective. This would be evident through observation of teacher-learner relationships. Also various respondents shared their perception on quality service delivery in pre-primary schools therefore providing the inside, outside as well as the ultimate perspective on quality as outlined by Lilian Katz.

\section{Research Methodology}

The study was conducted in Murang'a County, Kenya. The participants included all pre-school teachers estimated at 800 in 614 pre-primary schools in Murang'a County, 614 ECD Managers/Head teachers and 614 parents' representatives and 10 ECD County Officers. All the participants identified are involved in the running of ECDE in the county in different ways. A sample size of 194 was arrived at using various sampling techniques which are stratified random sampling, simple random and purposive sampling as illustrated in Table 1 below. The data was collected using questionnaires for teachers, interview guides for parents' representative and ECD officers and an observation schedule for the pre-primary environment.

Table 1. Sampling grid.

\begin{tabular}{ccccc}
\hline Categories of population & $\begin{array}{c}\text { Target/Sample } \\
\text { Population }\end{array}$ & Proportion & $\begin{array}{c}\text { Sampling } \\
\text { Procedure }\end{array}$ & $\begin{array}{c}\text { Sample } \\
\text { Size }\end{array}$ \\
\hline Pre-primary schools & 614 & $14 \%$ & $\begin{array}{c}\text { Stratified simple } \\
\text { Random sampling }\end{array}$ & 86 \\
Pre-Primary Teachers & 800 & $11 \%$ & $\begin{array}{c}\text { Purposive } \\
\text { Simple }\end{array}$ & 86 \\
Parents Representative & 86 & $10 \%$ & $\begin{array}{c}\text { Random sampling } \\
\text { Simple }\end{array}$ & 8 \\
$\begin{array}{c}\text { Head teachers/ECD } \\
\text { managers }\end{array}$ & 86 & $10 \%$ & $\begin{array}{c}\text { Random sampling } \\
\text { Simple }\end{array}$ & 8 \\
$\begin{array}{c}\text { ECD County officers } \\
\text { Total }\end{array}$ & 10 & $60 \%$ & Random Sampling & 6 \\
\hline
\end{tabular}

Source: Researcher (2017). 
This study employed a mixed methodology approach in which concurrent triangulation design was employed. The researcher collected and analyzed both quantitative and qualitative data sets simultaneously in a single data collection and analysis phase. Therefore, timing of data collection, analysis, and interpretation of both data was done at the same time (Creswell, 2008). The collected data was equally weighted since the researcher gave equal priority to both quantitative and qualitative data as both were equal sources of information for the study.

Furthermore, collected data was analyzed separately then results from both data sets were mixed during interpretation through comparisons in order to establish whether the results support or contradict each other (Weisner, 2005). The rationale for this design is that one data collection form supplied strength to offset the weaknesses of the other form hence depicting a clearer picture of the study problem. According to Creswell (2008) the design was appropriate as it allowed the researcher to gather information that uses the best features of both quantitative and qualitative data collection.

\section{Data Analysis Procedures}

Collected data was analyzed using both quantitative and qualitative data analysis techniques. Qualitative data analysis entailed the following procedures; developing a general category scheme of the participants' responses, identifying themes by sorting initial schemes into concrete categories and subcategories, checking for similarities and frequency of responses, reviewing the themes to establish how they contributed to the understanding of the relationship between ECD policy implementation and quality service delivery (Creswell \& Plano Clark, 2007). Finally, the findings were discussed using the themes established. The data collected was validated through triangulation and peer review.

Quantitative data analysis procedure applied the following steps; in the first step the data was prepared for analysis by coding it and cleaning data entry in the database, recoding any new variable for computer analysis and developing a codebook which outlined variables their definitions and numbers. The second step entailed analyzing the data using descriptive statistics such as frequencies and percentages. Then the data was analyzed inferentially using Spearman and Pearson to test study hypotheses at $p<0.05$ level of significance (Creswell \& Plano Clark, 2007).

\section{Results and Discussions}

The study sought to achieve the following objectives:

1) To establish the extent of monitoring and evaluation practices in pre-primary school in Murang'a county Kenya.

2) To investigate the relationship between monitoring and evaluation and quality service delivery in pre-primary schools in Murang'a County Kenya.

3) To establish thematically how monitoring and evaluation is conducted in pre-primary schools in Murang'a County Kenya. 


\subsection{Extent of Monitoring and Evaluation Practices in Pre-Primary Schools in Murang'a County Kenya}

To determine the extent of monitoring and evaluation practices in pre-primary school in Murang'a county Kenya. Pre-primary teachers were presented with a questionnaire which had eight items and the respondents answered using any of the following five terms: never rated as one which meant that practice is not there at all, rarely rated two which meant that the practice recurs only after a long interval that is more than one year, sometimes rated as three which meant that monitoring and evaluation is occasional and inconsistent, often rated four meaning that the practice is frequent that is every term and very often rated five meaning that the practice is done on monthly basis. The responses were as outlined in Table 2.

Table 2 presents the responses of Pre-primary teachers on the frequency of various monitoring and evaluation activities. The average frequencies in percentages on various monitoring and evaluation activities in Table 2 are graphically presented in Figure 1 for clarity.

Figure 1 shows that: $34 \%(n=29)$ of the preschools are monitored and evaluated occasionally and inconsistently, 30\% $(\mathrm{n}=26)$ are monitored regularly on termly basis, $14 \%(\mathrm{n}=12)$ are monitored and evaluated on monthly basis, $8 \%(\mathrm{n}$ $=7)$ of the Pre-primary schools are rarely monitored while $14 \%(n=12)$ of the Pre-primary schools are never monitored and evaluated. The analysis clearly shows that most of the Pre-primary schools in Murang'a County are monitored

Table 2. Frequencies in \% of monitoring and evaluation related activities.

\begin{tabular}{|c|c|c|c|c|c|}
\hline Items & $\mathrm{N}-1$ & $\mathrm{R}-2$ & S-3 & $\mathrm{O}-4$ & VO-5 \\
\hline $\begin{array}{l}\text { How frequently are Pre-Primary facilities in your centre } \\
\text { monitored or evaluated by DICECE or DQAS? }\end{array}$ & $10 \%$ & $27 \%$ & $31 \%$ & $26 \%$ & $6 \%$ \\
\hline $\begin{array}{l}\text { How frequently are you assessed while teaching by DICECE } \\
\text { or DQAS? }\end{array}$ & $11 \%$ & $14 \%$ & $37 \%$ & $31 \%$ & $7 \%$ \\
\hline $\begin{array}{l}\text { I normally receive a copy of the monitoring and evaluation } \\
\text { report from the DICECE/DQAS officer? }\end{array}$ & $29 \%$ & $14 \%$ & $28 \%$ & $15 \%$ & $14 \%$ \\
\hline $\begin{array}{l}\text { We do discuss the monitoring and evaluation report with } \\
\text { my immediate supervisor? }\end{array}$ & $20 \%$ & $13 \%$ & $29 \%$ & $22 \%$ & $16 \%$ \\
\hline $\begin{array}{l}\text { Do you ever make request or proposal to the administration } \\
\text { after assessment to improve on provision of learning facilities? }\end{array}$ & $14 \%$ & $8 \%$ & $34 \%$ & $30 \%$ & $14 \%$ \\
\hline $\begin{array}{l}\text { Do you utilize monitoring and evaluation reports to improve } \\
\text { your teaching skills? }\end{array}$ & $15 \%$ & $5 \%$ & $23 \%$ & $26 \%$ & $31 \%$ \\
\hline $\begin{array}{l}\text { Does the monitoring and evaluation report support you in } \\
\text { improving teacher-learner relationship? }\end{array}$ & $14 \%$ & $8 \%$ & $34 \%$ & $30 \%$ & $14 \%$ \\
\hline Are you ever motivated by the feedback received from & & & & & \\
\hline $\begin{array}{l}\text { DICECE and DQAS to improve children nutritional and } \\
\text { health environment? }\end{array}$ & $23 \%$ & $8 \%$ & $30 \%$ & $22 \%$ & $17 \%$ \\
\hline Average & $14 \%$ & $8 \%$ & $34 \%$ & $30 \%$ & $14 \%$ \\
\hline
\end{tabular}

Key N-Never, R-Rarely, S—Sometimes, O-Often, VO-Very Often. 


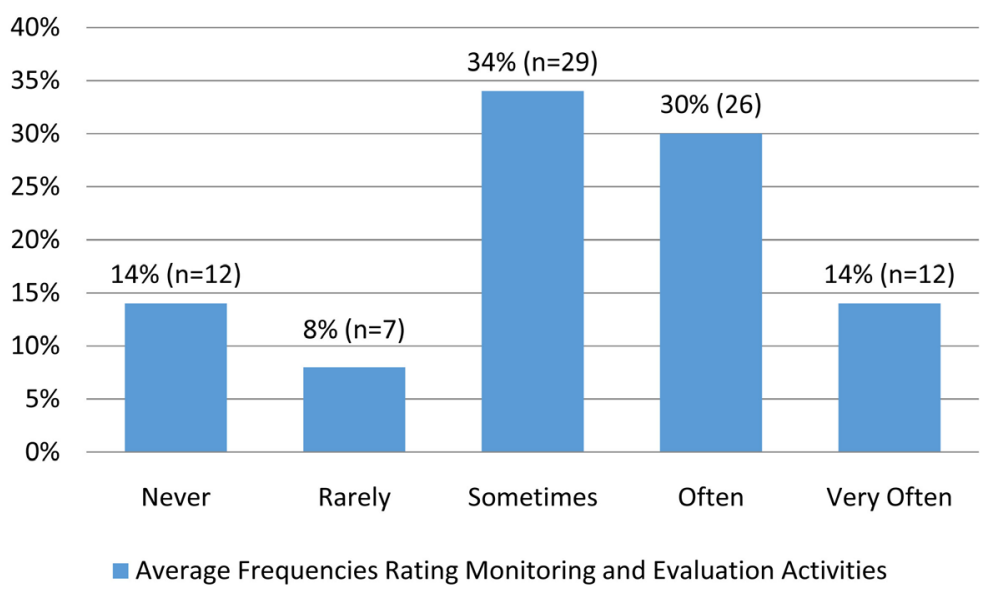

Figure 1. Average frequencies in percentages on monitoring and evaluation of pre-primary schools.

and evaluated occasionally and inconsistently. This implies that guidelines on monitoring and evaluation as stipulated in the ECD policy framework and the service guidelines are not adequately adhered to. This scenario creates room for variation in delivery of quality services in Pre-primary schools in Murng'a County. This is consistent to a study by (Tarsilla, 2014) who established that monitoring and evaluation in African countries is characterized by low funding. Subsequently, the objectives of monitoring and evaluation are rarely realized.

In Table 3, the researcher further established the perceptions of Pre-primary teachers about the influence of monitoring and evaluation on quality service delivery. The respondents provided responses for the five items in the table using the following terms: strongly disagree (1), disagree (2), not sure (3), agree (4) and strongly agree (5). On running descriptive analysis the frequencies in percentages from the eighty six Pre-primary teachers sampled were as outlined in Table 3.

Table 3 presents the frequency in percentages of Pre-primary teachers' perceptions regarding influence of monitoring and evaluation on quality service delivery. The frequencies on average in percentages on Table 3 are illustrated with a pie chart in Figure 2 depicting clearly the opinions of Pre-Primary teachers' as it regards influence of monitoring and evaluation on quality service delivery in Pre-primary schools.

The findings in Figure 2 above indicate that on average 17\% $(\mathrm{n}=15)$ of Pre-primary teachers strongly agreed with the items in Table 3, 51\% $(n=44)$ agreed, $6 \%(n=5)$ were not sure, $18 \%(n=15)$ disagreed and $8 \%(n=7)$ strongly disagreed. Majority of the respondents that is more than half agreed with the fact that monitoring and evaluation activities do impact significantly on quality service delivery in Pre-primary schools. However, their belief contradicts with the actual practice since the study established that Pre-primary schools are monitored and evaluated occasionally and inconsistently and for some never. This indicates that a gap exists between what is known through policy guidelines and actual practice. 


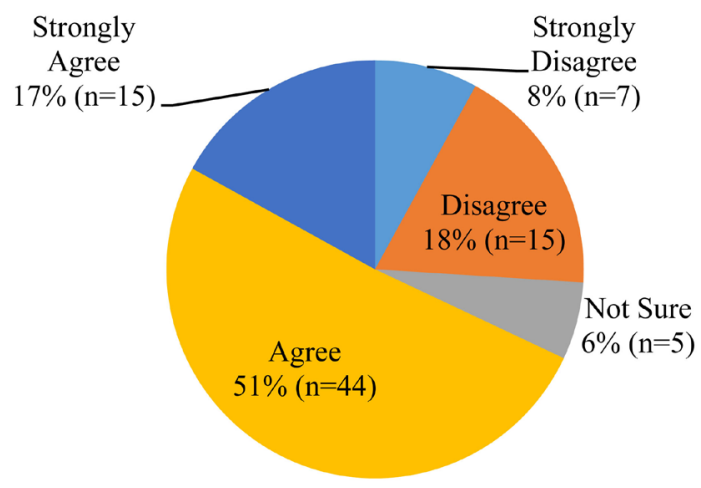

Figure 2. Average frequencies in $\%$ on influence of monitoring and evaluation on quality service delivery in pre-primary schools.

Table 3. Pre-primary teachers' perception of monitoring and evaluation influence on quality service delivery.

\begin{tabular}{|c|c|c|c|c|c|c|}
\hline \multirow{2}{*}{ S/NO } & \multirow{2}{*}{ ITEMS } & SD & $D^{\prime}$ & NS & A & $\mathrm{SA}$ \\
\hline & & 1 & 2 & 3 & 4 & 5 \\
\hline 1. & $\begin{array}{l}\text { monitoring and evaluation in my centre by } \\
\text { DICECE \& DQAS is satisfactory for ensuring there } \\
\text { is quality physical environment }\end{array}$ & $9 \%$ & $23 \%$ & $6 \%$ & $48 \%$ & $14 \%$ \\
\hline 2. & $\begin{array}{l}\text { monitoring and evaluation in my centre by } \\
\text { DICECE \& DQAS is satisfactory for ensuring there } \\
\text { is appropriate instructional environment }\end{array}$ & $8 \%$ & $20 \%$ & $8 \%$ & $49 \%$ & $15 \%$ \\
\hline 3. & $\begin{array}{l}\text { Monitoring and evaluation in my centre by } \\
\text { DICECE \& DQAS is satisfactory for ensuring there } \\
\text { is appropriate teacher-learner interaction. }\end{array}$ & $8 \%$ & $17 \%$ & $4 \%$ & $53 \%$ & $18 \%$ \\
\hline 4. & $\begin{array}{l}\text { Monitoring and evaluation in my centre by } \\
\text { DICECE \& DQAS is satisfactory for ensuring there } \\
\text { is proper nutritional environment. }\end{array}$ & $8 \%$ & $16 \%$ & $6 \%$ & $51 \%$ & $19 \%$ \\
\hline 5. & $\begin{array}{l}\text { Monitoring and evaluation in my centre by } \\
\text { DICECE \& DQAS is satisfactory for ensuring there } \\
\text { is a healthy environment. }\end{array}$ & $9 \%$ & $12 \%$ & $7 \%$ & $53 \%$ & $19 \%$ \\
\hline & Average & $8 \%$ & $18 \%$ & $6 \%$ & $51 \%$ & $17 \%$ \\
\hline
\end{tabular}

The findings are consistent with the study by Kamindo (2008) on instructional supervision in an era of change; policy and practice in primary education in Kenya. The study established that despite the legal backing and presence of policies supporting monitoring and evaluation the actual practice differs from the policy expectations. Descriptive findings of this study confirm the assertions since majority of the respondents perceive the practice of monitoring and evaluation to be important but in reality the practice is inconsistently seized.

\subsection{Influence of Monitoring and Evaluation on Quality Service Delivery in Pre-Primary Schools in Murang'a County Kenya}

To verify the possibility of relationship and the nature of relationship between monitoring and evaluation and quality service delivery in Pre-primary schools 
the hypothesis below was tested.

Hol There is no statistically significant influence of monitoring and evaluation on quality service delivery in Pre-primary schools in Murang'a County.

The hypothesis was tested in a two level process where the first process entailed establishing if there was any relationship between monitoring and evaluation of Pre-primary schools and quality service delivery. The second process focused on establishing if monitoring and evaluation have any significant influence on quality service delivery in preschools.

\subsubsection{Correlations between Monitoring and Evaluation with Quality Service Delivery}

Pearson correlation test was run and the outcomes on associations between the two variables are as outlined in Table 4.

According to Table 4, the results indicate that there exists a moderate positive correlation between monitoring and evaluation and quality service delivery in Pre-primary schools since $\mathrm{r}=0.545$. In addition the correlation is significant since $p<0.001, p<0.05$. This indicates that monitoring and evaluation are positively related to quality service delivery in Pre-primary schools. Therefore, as monitoring and evaluation practices are increased quality service delivery also increases. The next step of analysis established the association of the two variables as outlined in Table 5 .

\subsubsection{Regression Model, ANOVA and Coefficients of Determinations on Influence of Monitoring and Evaluation on Quality Service Delivery}

In the second process, a regression analysis was done and the results are presented in Table 5.

Table 5 indicates that $\mathrm{R}^{2}=0.297$ which is equivalent to $29.7 \%$ meaning that monitoring and evaluation practices accounts for $29.7 \%$ to the variation in quality service delivery in Pre-primary schools. ANOVA results indicate that (F (1, $84)=35.464, p<0.05, p<0.001)$ and coefficients of determinations shows that $\beta$ $=0.545, t=5.955 \& p=0.00001$. Therefore, monitoring and evaluation related activities are significant predictors of quality service delivery in Pre-primary

Table 4. Correlations of monitoring and evaluation with quality service delivery.

\begin{tabular}{cccc}
\hline & & monitoring and evaluation & Quality service delivery \\
\hline \multirow{2}{*}{$\begin{array}{c}\text { monitoring and } \\
\text { evaluation }\end{array}$} & Pearson Correlation & 1 & $0.545^{* *}$ \\
& Sig. (2-tailed) & & 0.000 \\
\hline $\begin{array}{c}\text { quality } \\
\text { service delivery }\end{array}$ & Pearson Correlation & $0.545^{* *}$ & 86 \\
& Sig. (2-tailed) & 0.000 & 1 \\
\hline
\end{tabular}

${ }^{* *}$ Correlation is significant at the 0.01 level (2-tailed). 
Table 5. Regression model, ANOVA and coefficients of determinations on influence of monitoring and evaluation on quality service delivery.

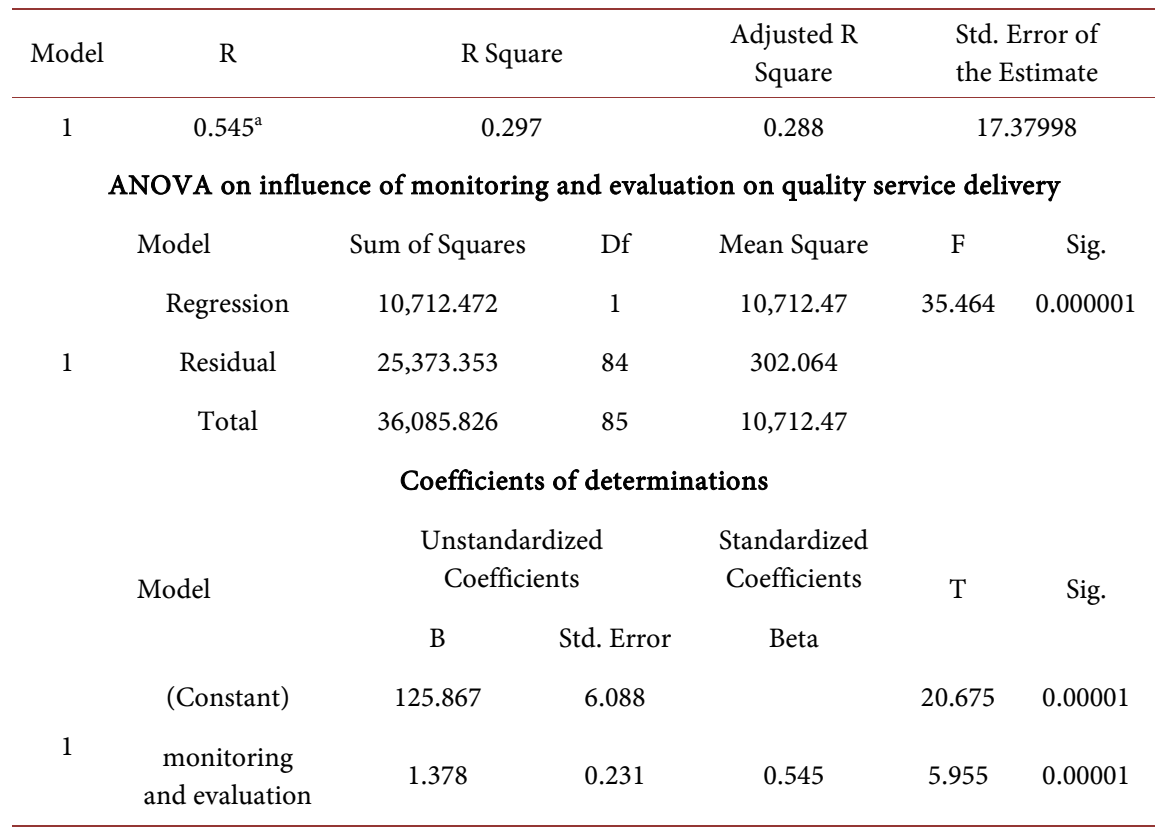

${ }^{a}$ Dependent Variable: Quality Service Delivery.

schools in Murang'a County. This means that monitoring and evaluation should be an exercise that is conducted regularly to improve quality service delivery in Pre-primary schools.

The findings implied that the level of monitoring and evaluation in terms of frequency, dissemination of evaluation reports and utilization of the same significantly contributes to quality service delivery in Pre-primary schools. Therefore, the null hypothesis was rejected. The findings are in agreement with the reviewed literature of (Mackay, 2006) who notes that the findings of monitoring and evaluation should be utilized by the relevant stakeholders to improve service delivery. This calls for development of an effective monitoring and evaluation system which provides the framework of what and who to monitor and the cost implications to enhance sustainability (Vitiello and Kools, 2010).

\subsection{Thematic Analysis on How Monitoring and Evaluation Is Conducted in Pre-Primary Schools in Murang'a County, Kenya}

The researcher conducted interviews amongst Head teachers, ECD county officers and parents' representatives to get more in-depth information about how monitoring and evaluation is conducted in Pre-primary schools. The interview guide for parents' representative had two questions which gathered information on monitoring and evaluation. The first question established if parents' are involved in ensuring that their children's school environment is appropriate and conducive for various activities at school.

The responses from parents' representatives indicated that majority $63 \%(\mathrm{n}=$ 5) of the parents' are not involved in monitoring and evaluation activities unless 
they are called upon by the teacher. One of the parents' representatives P5 said:

"Parents in this school are never involved in monitoring and evaluation activities unless called upon by the teacher to do so like in ensuring that the playground is appropriate for various play activities".

On interrogating further why it is so it was established that parents believe that it is the responsibility of the teacher to ensure that the school environment is conducive for the child. However, there were a few respondents $25 \%(\mathrm{n}=2)$ who reported that they are involved in monitoring and evaluation activities. The identified activities were like checking on the hygiene of the children's toilets and the safety of the playground. Furthermore, one of the parents' representatives reported that they were never involved in monitoring and evaluation activities.

In view of the responses from parents' representatives it is clear that very few parents are actively engaged in monitoring and evaluation activities in order to ensure quality service delivery in Pre-primary schools. However, it is encouraging to note that majority of the parents can be involved if sensitized and empowered by the teachers to do so. In addition, the fact that there are some parents not involved at all indicates presence of some parents who are ignorant of this functionality which is very instrumental toward enhanced quality service delivery in Pre-primary schools.

The second question in the same parents' representative interview guide established whether parents were aware of other persons who were involved in ensuring that the school environment was appropriate for the child. Majority of the respondents $63 \%(n=5)$ reported that there were other persons involved in monitoring and evaluation of the school environment. The identified persons were the school committee, members of the parliament, community, and the church. It was interesting to note that none of the respondents identified ECD county officers as key people in monitoring and evaluation. The remaining percentage 37\% $(n=3)$ of the respondents reported that they were not aware of other persons that are involved in monitoring and evaluation.

On scrutinizing the responses for the second question, it was clear that majority of the parents were not really informed on matters related to monitoring and evaluation. The results indicated that they were not aware of ECD county officers as the persons mandated in the ECD policy to spearhead monitoring and evaluation in Pre-primary schools. This can be attributed to lack of sensitization among parents about the policy guidelines and also ignorance on various policy issues.

The researcher further interviewed ECD county officers', and head teachers'/ECD managers. The first question in the interview guide for the respondents established how monitoring and evaluation practices are conducted by ECD county officers in the Pre-primary schools. The question probed about frequency of monitoring, dissemination and utilization of the evaluation report. Various responses as illustrated below pointed towards the fact that the practice is rare and non-existent in some Pre-primary schools specifically private institution. 
Through interrogation of the frequency of monitoring and evaluation and dissemination of evaluation reports the following issues were recorded from various respondents interviewed. Respondent $\mathrm{Z}$ had the following to say.

"Before the introduction of the county government, each district had two ECD officers who were known as DICECE officers. The officers used to visit $E C D$ centres regularly twice per term. They would prepare a report of their observations and share with the head teacher sometimes in presence of the Pre-primary teacher. In addition, during their consecutive visit they would follow up to ensure issues raised are addressed".

The narrative by the respondent was a good story presenting a close to ideal practice in monitoring and evaluation of Pre-primary schools for enhanced delivery of quality services. However, the story was followed by a contradicting distressing reality which was as follows:

"After the introduction of county government the positions of DICECE officers were scrapped and those who were willing to remain with the Teachers' Service Commission (TSC) were redeployed to other offices, some went back to classroom teaching while others opted to shift to county government as ECD officers. This was a shift which the county government was not adequately prepared for as a result the practice of monitoring and evaluation in Pre-primary schools was affected such that currently the practice is no longer there and in case it's there it's done once per year'.

This implied that the practice which is meant to ensure policy guidelines are adhered to is occasional and inconsistent. This was in agreement with the descriptive findings where majority of the respondents noted that monitoring and evaluation is done sometimes despite the fact that it is an important practice meant to enhance delivery of quality services. These are sentiments that were agreed upon by $63 \%(n=5)$ of the respondents.

On the contrary, respondent $\mathrm{W}$ who was an ECD manager had this to say:

"Since the school was established six years ago we have never received a DICECE officer or an ECD county officer monitoring and evaluating the standard of the school. The only time they visit is when they have a practicing teacher for assessment which is a requirement for students to complete an ECDE course".

This report contradicts to the at least once per year monitoring and evaluation practice reason being the respondent was from a private school and it emerged out that the county government does not bother with monitoring and evaluation of private institutions since similar sentiments were echoed by respondents from private institutions. The findings concur with a study by Kamindo (1998) on Head teachers' instructional supervisory practices in primary schools in Ngong Division, Kajiando District in Kenya. The study revealed that supervisors hardly monitored and evaluated private schools except for the purpose of registration. However, it is important to note that respondent $\mathrm{V}$ who works in a private school reported:

"Our school is usually monitored frequently since the government is con- 
cerned about the welfare of children especially in academic performance so in case of decline officers concerned with monitoring and evaluation express a lot of concern and probes for explanation".

This was quite unexpected. However, it was noted that the concern is for children in primary school and not Pre-primary children. Therefore, the views agree with those of respondent $\mathrm{W}$. In addition, the response indicates the overemphasis on monitoring in the pre-primary schools concurring with earlier sentiment by Respondent $\mathrm{Z}$ who noted:

"Monitoring and evaluation in the primary sector currently is well done though very involving".

The scenario above brings out differences which exist in delivery of services to children in Pre-primary schools and those in primary schools. This is attributed to the fact that the first is under the county government and the latter under central government (TSC). This causes disharmony or disconnect which was resonated by one of the head teachers' who felt that county government at times bypasses them when they connect directly to the Pre-primary teacher without their knowledge while as they are the officers in charge of the same Pre-primary teacher in the implementation of the policy on the ground. This indicated poor coordination among the officers who should be involved in monitoring and evaluation. A challenge experienced in many African countries as it was noted by Hauge (2003) in a study conducted in Uganda.

The second question established how monitoring and evaluation practices identified influence quality service delivery in terms of ensuring quality physical environment, instructional environment, social environment, nutritional environment, and healthy environment. All the respondents reported that the practice enhances continuous improvement of the physical, social, instructional, nutritional and health environment.

However, it was quite unfortunate that most of the respondents unanimously reported that the exercise of monitoring and evaluation is rarely done by the ECD county officers agreeing with the $8 \%$ Pre-Primary teachers who reported that the exercise is rare while as contradicting with more than $90 \%$ of the Pre-Primary teachers who reported otherwise. The variation can be attributed first to the fact that some of the Pre-Primary teachers reported that monitoring and evaluation is conducted often with the motive of protecting their seniors and secondly because ECD county officers do visit the Pre-primary schools but while undertaking other duties rather than monitoring and evaluation. Therefore, it is a fact that monitoring and evaluation in Pre-primary schools is occasionally and inconsistently seized.

ECD county officers interviewed reported that monitoring and evaluation of Pre-primary schools is rarely done because of a number of issues which emerged from all the officers interviewed. The first issue was lack of facilitation to Pre-primary schools within their jurisdiction and the fact that there are too many Pre-primary schools under only one officer. Respondent $\mathrm{Y}$ noted that:

"We are understaffed hence the best we can do is once per year per schoop". 
Consequently, the teaching process and facilities are rarely inspected to ensure that they are of the required standards. Secondly, the officers within the county are poorly coordinated implying there is lack of team work which would enhance proper planning geared towards enhancing monitoring and evaluation practices.

The conversations with the various respondents point to the fact that monitoring and evaluation at present under the dispensation of the county government is rarely done. As a result, a lot of notable variations in delivery of quality services were observed. Also, through inferential statistics it was established that monitoring and evaluation accounts for approximately $30 \%$ of the variation in quality service delivery in Pre-primary schools. This implies that monitoring and evaluation practices are worthy attention from various stakeholders as outlined in the policy (Republic of Kenya, 2006a). However, stakeholders who according to the policy can support monitoring and evaluation like parents and community are never trained to develop their capacity. Consequently, the duty is fully pegged on ECD county officers who are few and under facilitated hence the mismatch between policy guidelines and the practice.

Inadequate monitoring and evaluation was further pointed out by respondent $P$ who said that:

"County government funds feeding programme however there are no follow ups that are done to ensure that the goals of the feeding programmes are achieved hence there are variation in implementation of the feeding programmes in Pre-primary schools in Murang' a County".

The sentiments were true since in the same county the researcher observed some public Pre-primary schools where children were not fed at school despite the fact that Murang'a county government was funding the feeding programmes. This implies that the county government effort toward enhancing nutritional and health environment do not benefit all the children in the county.

The discussion with the various respondents brings out the following themes about monitoring and evaluation.

1) Parents who are key stakeholders in implementation of ECD policy are ignorant of the monitoring and evaluation practices of pre-primary schools and rarely involved in the process.

2) Private pre-primary schools are not monitored and evaluated by ECD county officers.

3) Monitoring of the primary sector is regular while that of pre-primary school is inconsistent.

4) Monitoring of pre-primary schools was negatively affected with deployment of DICECE officers by the government of Kenya.

5) Monitoring and evaluation of pre-primary schools in Kenya is lowly funded and ECD county officers are overloaded with many schools under their jurisdiction which they are not able to monitor effectively.

The findings are consistent to a study by (Wawire, 2006) in a study about factors that influence the quality and relevance of early childhood in Kenya: mul- 
tiple case studies of Nairobi and Machakos districts. The study revealed that there were low levels of supervision and inspection which is further hindered by challenges like lack of access to Pre-Primary especially in remote areas.

\section{Summary of Findings and Conclusions}

The results of this research paper revealed the extent of monitoring and evaluation of pre-primary schools in Murang'a County. Inferential analysis indicated that monitoring and evaluation significantly relates to the quality of services delivered in Pre-primary schools. Descriptive analysis revealed that monitoring and evaluation in Pre-primary is conducted sometimes meaning it is occasional and inconsistent. However, Pre-primary teacher's perceptions indicated that monitoring and evaluation is an aspect that would enhance quality service delivery in Pre-primary schools. Inferential analysis revealed that a moderate positive correlation $(\mathrm{r}=0.545)$ exists between monitoring and evaluation and delivery of quality services in Pre-primary schools. Interviews conducted agreed with the descriptive and inferential analysis since respondents reported that the practice is rare in some schools and inconsistent in most of the schools. They also agreed with the fact that if monitoring and evaluation was conducted regularly, delivery of quality services would be realized and observable in children's learning environments. Majority of respondents noted that physical, social, instructional and social environment would be enhanced with adequate monitoring and evaluation. However, it was clear that the current frequency in monitoring and evaluation creates room for failure to adhere policy guidelines as stipulated in the ECD policy framework.

\section{Recommendations}

The government through county governments should hire more ECD county officers to enhance monitoring and evaluation of ECD policies implementation since the officers in place are not able to regularly monitor pre-primary schools at their areas of jurisdiction comprehensively because they are too many. In addition, County government should allocate more funds to facilitate monitoring and evaluation practices by the ECD officers on the ground since this was cited as a factor hindering regular monitoring of Pre-primary schools.

Officers in charge of monitoring and evaluation should ensure that the reports of the exercise are disseminated to the right offices for continuous improvement in delivery of quality services in Pre-primary schools.

\section{Conflicts of Interest}

The authors declare no conflicts of interest regarding the publication of this paper.

\section{References}

ACECQA (2013). Guide to the National Quality Standard. http://www.saasso.asn.au/wp-content/uploads/2013/11/NQF-Guide-to-the-National-Q 
uality-Framework-September-2013.pdf

Bronfenbrenner, U. (1979). The Ecology of Human Development: Experiments in Nature and Design. Cambridge, MA: Harvard University Press.

Carman, J. (2007). Evaluation Practice among Community Based Organizations: Research into the Reality. American Journal of Evaluation, 28, 60-75. https://doi.org/10.1177/1098214006296245

Creswell, J. (2008). Educational Research: Planning, Conducting, and Evaluating Quantitative and Qualitative Research. Upper Saddle River, NJ: Pearson Education, Inc.

Creswell, J., \& Plano Clark, V. (2007). Designing and Conducting Mixed Methods Research. Thousand Oaks, CA: Sage.

Dawes, A., Bray, R., Kvalsvig, J., Kafaar, Z., Rama, S., \& Richter, L. (2004). Going Global with Indicators of Child Well-Being: Indicators of South African Children's Psychosocial Development in the Early Childhood Period: Phase 1 \& 2 Report. (Commissioned by United Nations Children's Fund, (UNICEF), South Africa). http://ktree.hsrc.ac.za/doc_read_all.php?docid=1209

Fowler, A. (1997). Striking a Balance: A Guide to Enhancing the Effectiveness of NonGovernmental Organizations in International Development. London: Earthscan.

Harvard Centre on the Developing Child (2010). The Foundations of Lifelong Health Are Built in Early Childhood. Cambridge, MA: Author.

Hauge, A. (2003). The Development of Monitoring and Evaluation Capacities to Improve Government Performance in Uganda. ECD Working Paper Series No. 10. OED. Washington, D.C.: World Bank.

Hwang, H., \& Powell, W. W. (2009). The Rationalization of Charity: The Influences of Professionalism in the Non-Profit Sector. Administrative Science Quarterly, 54, 268-298.

https://doi.org/10.2189/asqu.2009.54.2.268

Kamindo, C. (1998). Headteachers' Instructional Supervisory Practices in Primary Schools in Ngong Division, Kajiando District in Kenya. Unpublished M.Ed Thesis, Nairobi: Kenyatta University.

Kamindo, C. (2008). Instructional Supervision in an Era of Change; Policy and Practice in Primary Education in Kenya. PhD Thesis, Durham: Durham University.

Lahey, R. (2005). A Comparative Analysis of Monitoring and Evaluation in Four Selected Countries: Canada, United States, Australia and United Kingdom. Unpublished Manuscript.

Lu, C., Black, M., \& Richter, L. (2016). Risk of Poor Development in Young Children in Low-Income and Middle Income Countries: An Estimation and Analysis at the Globe, Regional, and Country Level. The Lancet Global Health, 4, e916-e922. https://doi.org/10.1016/S2214-109X(16)30266-2

Mackay, K. (2006). Institutionalization of Monitoring and Evaluation Systems to Improve Public Sector Management. Washington DC: The World Bank. http://www.worldbank.org/ieg/ecd

Moige, O. (2012). Assessment of Parents' Level of Satisfaction with the Quality of PrePrimary Education in Lang'ata District, Nairobi County, Kenya. Unpublished Thesis, Nairobi: Kenyatta University.

Muchau, J. (2015). Teacher-Related Factors and Errors Preschool Children Make in Learning English Language in Murang'a County Schools. Unpublished Thesis, Nairobi: University of Nairobi.

Murang'a County Initiative (2015). Strategies for Improving the Standards of Education in Murang'a County MCI Kenya. 
Murunga, J. (2016). Devolving Early Childhood Development Education in Kenya: Policy Challenges and Opportunities.

http://www.academia.edu/11616174/devolving_early_childhood_development_educati on_in_kenya_policy_challenges_and_opportunities

Pence, A., \& Pacini-Ketchabaw, V. (2008). Discourses on Quality Care: The Investigating "Quality" Project and the Canadian Experience. Contemporary Issues in Early Childhood, 9, 241-255. https://doi.org/10.2304/ciec.2008.9.3.241

Republic of Kenya (2006a). National Early Childhood Policy Framework. Nairobi: Government Printer.

Republic of Kenya (2006b). Early Childhood Development Service Standard Guidelines for Kenya. Nairobi: Government Press.

Royal College Position Statement (2014). Early Childhood Development Royal College Position Statement.

https://www.oise.utoronto.ca/atkinson/UserFiles/File/News/ECD-RoyalCollegePhy.pdf

Tarsilla, M. (2014). Evaluation Capacity Development in Africa: Current Landscape of International Partners' Initiatives, Lessons Learned and the Way Forward. African Evaluation Journal, 2, a89. https://doi.org/10.4102/aej.v2i1.89

UN (2000). Millennium Development Goals. http://www.unaids.org/en/aboutunaids/unitednationsdeclarationsandgoals/2000millen niumdevelopmentgoals

UNESCO (2000). The Dakar Framework for Action. http://unesdoc.unesco.org/images/0012/001211/121147e.pdf

UNICEF (2011). UNICEF Annual Report 2011 EN 060112. http://www.unicef.org/nutrition/files/UNICEF_Annual_Report_2011_EN_060112.pdf

UNICEF (2017). Early Moments Matter for Every Child. https://www.unicef.org/media/files/UNICEF_Early_Moments_Matter_for_Every_Chil d_report.pdf

Vitiello, V. E., \& Kools, M. (2010). Good Governance of Early Childhood Development Programmes in Developing Countries: The Need for a Comprehensive Monitoring System. Innocenti Discussion Paper No. IDP 2010-02, Florence: UNICEF Innocenti Research Centre.

Wawire, V. (2006). Factors That Influence the Quality and Relevance of Early Childhood Education in Kenya: Multiple Case Studies of Nairobi and Machakos District. Unpublished PhD Thesis, Nairobi: Kenyatta University.

Weisner, T. (2005). Discovering Successful Pathways in Children's Development: Mixed Methods in the Study of Childhood and Family Life. Chicago, IL: University of Chicago Press. 